\title{
Red dragon fruit (Hylocereus polyrhizhus) in preventing collagen decrease in menopause induced rats skin
}

\author{
Eswariy Chandramogan \\ IWayan Sugiritama \\ I Gusti Ayu Dewi Ratnayanti \\ I Gusti Nyoman SriWiryawan \\ Ida Ayu Ika Wahyuniari
}

Department of Histology, Faculty of Medicine, Udayana University,

\section{Cite this article:}

Chandramogan E, Sugiritama IW, Ratnayanti IGA, Wiryawan IGNS, Wahyuniari IAI. Reddragon fruit (Hylocereus polyrhizhus) in preventing collagen decrease in menopause induced rats skin. Neurologico Spinale Medico Chirurgico. 2020;3(1):5-8. DOI:10.36444/nsmc. v3il.90

Corresponding author:

Eswariy Chandramogan

Faculty of Medicine, Udayana University

JL. PB Sudirman, Dangin Puri Kelod, Denpasar Barat,

Kota Denpasar, 80232

Bali, Indonesia

E-mail: eswariy_2897@yahoo.com

\begin{abstract}
Background: Skin aging in menopause women was due to fewer collagen numbers in cells and antioxidants are necessary for inhibiting the process of skin aging due to oxidative stress. Red dragon fruits, which plant in Indonesia, was known to have a high concentration of antioxidants. This study aimed to assess the ethanol extract of red dragon fruit skin effects on the number of collagens on the skin of female Wistar rats which has been ovariectomized.
\end{abstract}

Methods: This experimental research was a post-test only control group design that was conducted on 30 female Wistar rats. Groups were divided into control (P0), 5\% ethanol extract (P1), and $15 \%$ ethanol extract concentrations (P2). The dosage was given orally to the rats and left for observation for 30 days. The number of collagens was observed and calculated on visual evaluation of the skin biopsy under a light microscope.

Results: The result showed a significant difference between treatment groups and control $(\mathrm{p}<0.05)$. The number of collagen are higher in P2 $(83.03 \pm 4.84)$ and P1 $(77.26 \pm 5.06)$ than P0 $(57.73 \pm 5.04)$.

Conclusion: Ethanol extract of red dragon fruit skin could prevent the number of collagen decrease in menopause induced rat skin.

Keywords: skin aging, menopause, ovariectomized, antioxidant, oxidative stress

\section{Introduction}

Menopause is the time when the menstrual period of a woman stops permanently and it happens when she get older. The median age of women who reach menopause is Asia ranges from 42.1 to 49.5 years. The women who reach menopause, will have hormonal level changes, therefore, the level of estrogen in the body decreases drastically. When estrogen decreases, the hormone function and antioxidant properties decreases and causes skin changes. ${ }^{1}$

Skin is the largest organ in the body which significantly affected by the aging process and menopause. The hypoestrogenism state influences dermal cellular metabolism. Hypoestrogenism is known as estrogen deficiency in the blood. Hypoestrogenism results in thinner skin increase the number and depth of wrinkles and increase skin dryness. ${ }^{2}$ Collagen is a protein made up of amino acids that hold all tissues together like cement found in skin cells. The first five years after menopause, the skin loses up to $30 \%$ of its collagen. When estrogen decrease, the skin becomes thinner with decreased collagen content. ${ }^{3}$

The estrogen depletion causes downregulation of antioxidant gene expression, which activates the free radicals. Free radicals are also known as reactive oxygen species (ROS). ROS are 
highly reactive molecules that cause oxidative stress in skin cells. The accumulation of reactive oxygen compounds increases the matrix metalloproteinase (MMP). Collagen can be directly destroyed by reactive oxygen compounds or through induction of MMP. This oxidative stress in skin cells leads to change in collagen fibers which causes collagen degradation and contribute to skin aging. ${ }^{4}$

Phytoestrogen is an estrogen compound obtained from red dragon fruit (Hylocereus polyrhizhus) containing a high level of anthocyanin in which is an alternative for estrogen replacement therapy. Phytoestrogens imitate estrogen because it has a very similar chemical structure to the body's estrogen. When phytoestrogens enter the body, the estrogen receptors of the body treat them as estrogens and maintain the estrogen level in blood. ${ }^{5}$ Anthocyanin is rich in antioxidant properties where it protects against skin damage by inactivating highly reactive molecules that form during menopause and causing significant cell, tissue and chain reaction to damage. Based on the research, red dragon fruit (Hylocereus polyrhizus) is one of the fruits that are rich in anthocyanin. An experiment is taken to prove the role of red dragon fruit skin as its rich in anthocyanin in preventing skin aging in a menopause woman. ${ }^{6}$

\section{Method}

The list of materials is as follows. Red dragon fruit skin is extracted to obtain 30 grams of ethanol extract. Thirty female Wistar rats aged 2-3 months old with a weight range of 180-220 grams (healthy rats), aquadest, ketamine, betadine, incision knife, gentamicin, and $96 \%$ ethanol were prepared accordingly. Ethical clearance was retained based on the safety of animal subjects during the whole experiment.

Ovariectomy on 30 female Wistar rats was carried out according to the modified Ingle DJ and Grith JQ method. Red dragon fruit (Hylocereus Polyrhizhus) skin is extracted and $96 \%$ ethanol added to obtain 30 grams red dragon fruit skin ethanol extract. A total of 30 samples are divided into three groups which are the control group (P0), 5\% red dragon fruit skin ethanol extract group (P1), and 15\% red dragon fruit ethanol extract group (P2). The ethanol extract is given orally to the 30 samples. Production of histological preparation through female Wistar rat skin biopsy was done to obtain a $5 \mathrm{~mm}$ skin tissue. Staining the skin tissue on the glass object with Picrosirius Red. Observation results on the amount of collagen expression were carried out by the digital analysis method with 400x magnification using a light microscope. The number of collagen using Adobe Photoshop CS3 and Image J was calculated.

Descriptive analysis is conducted to analyze the mean, median, and standard deviation values. Then, data obtained from the results of the study first carried out the homogeneity test (Levene's statistics) and normality test (Shapiro-Wilk test) to determine the statistical test used. Data that meets the requirements of normality and homogeneity is carried out by parametric statistical test, One Way Anova and followed by LSD test from Post Hoc. All data analysis uses SPSS for Windows version 22.0 software.

\section{Result}

The number of collagens on the dorsal skin of the Female Wistar Rat, observed under a light microscope using 400x magnification, showed the groups P2 and P1 had a higher number of collagens than group P0 (Figure 1).

The average number of collagen in group P0, P1, and P2 was $57.73 \pm 5.04,77.26 \pm 5.09,83.03 \pm 4.84$, respectively (Table 1). The number of collagen in female Wistar rat skin in P0, P1, and P2 was tested for normality using the Shapiro-Wilk test, and they were normally distributed ( $>0.05)$. Then, the number of collagen were tested for homogeneity using Levene's Test that showed homogenous data with p-value 0.937 . Subsequently, It was analyzed by one way ANOVA method and showed a significant difference in the number of collagen between P0, P1, and P2 ( $\mathrm{p}=0.001)$, as showed in Table 2 . Statistical analysis of the number of collagen in experimental animals was continued using a post hoc test that found the cell assessment data differed significantly $(\mathrm{p}<0.05)$ between groups P0 (Control), P1 (5\%), and P2 (15\%) (Table 3).
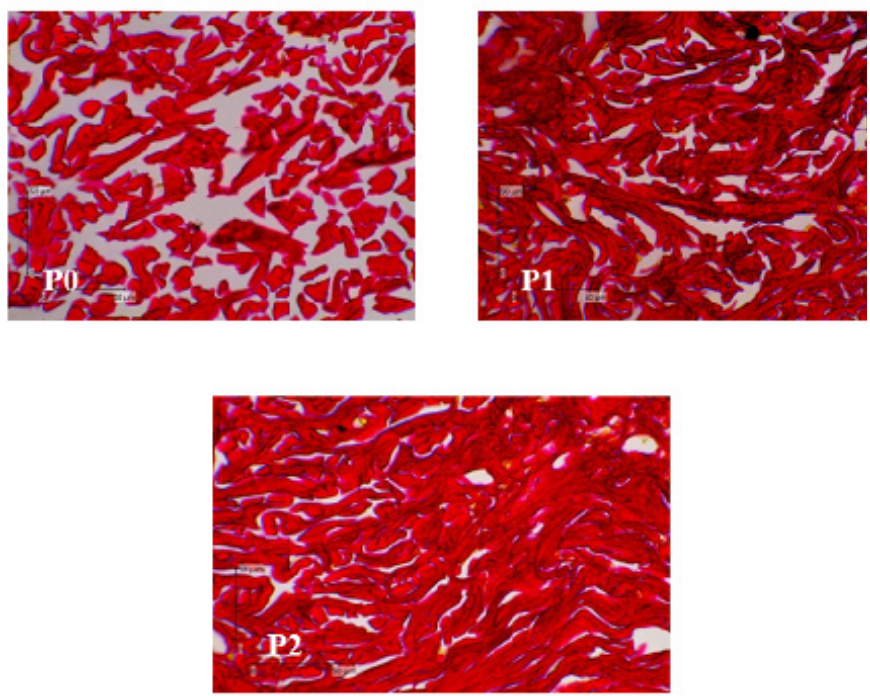

Figure 1. Results of number of collagens on the dorsal skin of female Wistar (400x magnification). It showed the groups P2 (Red Dragon fruit 15\%) and P1 (Red Dragon fruit 5\%) has a higher number of collagens than group P0 (normal saline).

Table 1. Descriptive test results of \% collagen in female Wistar rat.

\begin{tabular}{llllllll} 
Treatment & Group & Total Sample (n) & Mean & STD & Median & Minimum & Maximum \\
& & & & & & & \\
\hline Post Test & P0 & 10 & 57.73 & 5.04 & 57.60 & 50.56 & 66.61 \\
& $($ Control $)$ & & & & & & \\
& P1 & 10 & 77.26 & 5.09 & 75.89 & 72.13 & 86.56 \\
& $(5 \%)$ & & & & & & \\
& P2 & 10 & 83.03 & 4.84 & 84.02 & 75.14 & 89.32 \\
& $(15 \%)$ & & & & & & \\
\hline
\end{tabular}

STD: standard deviation 
Table 2. Result of average \% of collagen on skin of female Wistar rat analysed by using One-Way ANOVA method.

\begin{tabular}{llll}
\hline & Sum of Squares & Mean Square & Sig (p) \\
Between & 3516.312 & 1758.156 & 0.000 \\
Groups & & & \\
Within & 672.731 & 24.916 & \\
Groups & & & \\
Total & 4189.043 & & \\
\hline
\end{tabular}

Table 3. Post-Hoc result of average \% of collagen on skin of female Wistar rat analysed by using Least Significant Difference (LSD) test.

\begin{tabular}{llll}
\hline Groups & P0 & P1 & P2 \\
\hline P0 & - & 0.000 & 0.000 \\
P1 & 0.000 & - & 0.015 \\
P2 & 0.000 & 0.015 & - \\
\hline
\end{tabular}

\section{Discussion}

The differences of collagen number in this study was analyzed in the menopause model using ovariectomy rats. During menopause, the ovaries fail to produce enough hormones and the level of estrogen drops drastically causing skin aging. Hypoestrogenism is referred to estrogen deficiency that causes cell damage and resulting in cell apoptosis. Hence, the skin will be wrinkled and dry. ${ }^{2}$

Data from the treatment of 5\% and $15 \%$ concentration of ethanol extract of red dragon fruit skin showed the number of collagens in rats increased significantly compared to the controlled group. Thus, the administration of red dragon fruit skin ethanol extract in a greater percentage can increase the number of collagens.

The presence of anthocyanins in red dragon fruit skin functions as phytoestrogen and antioxidant. Phytoestrogen increases the estrogen level naturally and anthocyanin as antioxidant inhibits free radicals by acting as a scavenger. This reduces the oxidative stress in the back skin of the female Wistar rat. ${ }^{7}$ The result in this study is similar to Nanashima et al., ${ }^{8}$ about "The blackcurrant anthocyanins in increasing level of collagen, elastin and hyaluronic acid in human skin fibroblasts and ovariectomized rats". Anthocyanin in the blackcurrant managed to increase the collagen levels. Secondly, research by Saimin et al., ${ }^{4}$ about "The effect of tomato juice on the expression of matrix metalloproteinase-2 (MMP-2) and type 1 collagen on the vaginal wall of the menopausal rats". The antioxidant in tomato juice reduces the expression of MMP-2 and increases the expression on type 1 collagen.Thirdly, research by Tahir et al., about "Evaluation of tropical red dragon fruit extract effect (Hylocereus Polyrhizus) on tissue granulations on Wistar rats". Antioxidant in red dragon fruits reduces the tissue granulation on the wound by acting as a scavenger. Lastly, research by Li et al., ${ }^{10}$ about "Bilberry anthocyanin improves the serum cholesterol in aging perimenopausal rats via the estrogen receptor signaling pathway". Anthocyanin has a great effect on improving serum cholesterol in natural aging through the estrogen receptor signaling pathway.

Estrogen plays a role as a hormone and antioxidant. Estrogen is a hormone that appears to aid in the prevention of skin aging. The reproductive hormone prevents a decrease in skin collagen in postmenopausal women and maintains skin thickness. Estrogen also acts as an antioxidant that inhibits the oxidation in the body. Once estrogen decrease, the antioxidant decrease is causing the oxidation between free radicals to happen freely. ${ }^{11}$ Free radicals are also known as reactive oxygen species (ROS). Collagen can be directly destroyed by reactive oxygen compounds or through induction of a group of enzymes that play a role in the degradation of collagen, namely matrix metalloproteinase (MMP). The accumulation of reactive oxygen compounds will increase the matrix metalloproteinase-1 (MMP-1) and matrix metalloproteinase-2 (MMP-2). MMP-1 will break down collagens type I while MMP-2 breaks down gelatin, elastin, fibronectin, and collagen type I, IV and V. This damage to collagen type I and IV will result in a decrease in collagen products in the skin. ${ }^{12}$

Phytoestrogen property in anthocyanin has an anti-aging effect on the skin. Phytoestrogens imitate estrogen because it has a very similar chemical structure to the body's estrogen. When phytoestrogens enter the body, the estrogen receptors of the body treat them as estrogens. ${ }^{10}$ Previous study also found that anthocyanin induces proliferation of fibroblast, thereby increasing collagen synthesis in the skin. Moreover, the antioxidant property in anthocyanin significantly increases the expression of collagen type I and decreases MMP-1 and MMP-2 on the skin of Wistar rats, which allowed to experience additional age. ${ }^{13}$ This study proves a positive correlation between the dose of red dragon fruit skin ethanol extract and increasing of collagen type I expression. The higher the dose of red dragon fruit skin ethanol extract, the higher the collagen type I expression.

There are several limitations to this research. Mainly is that the phytochemical test was not conducted directly by researchers. Therefore, the types of antioxidants in red dragon fruit skin is not known. Moreover, shaving can cause injury to the back skin of experimental animals which can influence the reading of the number of collagens.

\section{Discussion}

Based on the results of the research that has been done, it could be concluded that $5 \%$ and $15 \%$ dose of ethanol extract to red dragon fruit skin could increase the number of collagens in ovariectomy Wistar rat. Further research may use the active compound of dragon fruit skin to elucidate its role in skin aging.

\section{Acknowledgment}

The authors would like to thank the supervisors in the Histology Department of Faculty of Medicine, Udayana University, for all the technical assistance and valuable discussions during this study. 


\section{References}

1. Palacios S, Henderson VW, Siseles N, et al. Age of menopause and impact of climacteric symptoms by geographical regio. Journal Climacteric. 2010;13(5):419-28. DOI: 10.3109/13697137.2010.507886

2. Thronton M J. Estrogens and aging skin. Journal Dermato-Endocrinology. 2013;5(2):264-70. DOI: 10.4161/derm.23872

3. Varani J, Dame M K, Rittie L, et al. Decreased collagen production in chronologically aged skin: roles of age dependent alteration in fibroblast function and defective mechanical stimulation. The American Journal of Pathology. 2006;168(6):1861-68. DOI: 10.2353/ajpath.2006.051302

4. Saimin J, Hendarto H, Soetjipto S. The effect of tomato juice on the expression of matrix metalloproteinase-2 (MMP-2) and type-1 collagen on the vaginal wall of the menopausal rats. Bali Medical Journal. 2019;8(3):707-12. DOI: 10.15562/bmj. v8i3.1277

5. Yuwono J, Sugiritama W I, Mayun G, et al. Efek pemberian ekstrak ethanol ubi jalar ungu (Ipomoea batatas L) terhadap ketebalan dan diferensiasi sel epitel vagina tikus betina yang mengalami ovariektomi di Laboratorium Histologi Fakultas Kedokteran Universitas Udayana periode Oktober-Desember 2017. E-Jurnal Medika Udayana. 2018;7(5): 203-10.

6. Khoo H E, Azlan A, Tang S T, et al. Anthocyanidins and anthocyanins: colored pigments as food, pharmaceutical ingredients, and the potential health benefits. Journal of Food \& Nutrition Research. 2017;61(1):1361779. DOI: 10.1080/16546628.2017.1361779

7. Vijayakumar R, Gani SSA, Zaidan UH, et al. Optimization of the antioxidant potentials of Red Pitaya peels and its in vitro skin whitening properties. Molecular Diversity Preservation International Journal. 2018;8(9):1516. DOI: 10.3390/app8091516

8. Nanashima N, Horie K, Maeda H, et al. The blackcurrant anthocyanins in increasing level of collagens, elastin and hyaluronic acid in human skin fibroblast and ovariectomized rats. Journal of Department of Bioscience and Laboratory Medicine. 2018; 10(32):345-75. DOI: 10.3390/molecules23010074

9. Tahir T, Bakri S, Pattelongi I, et al. Evaluation of topical red dragon fruit extract effect (Hylocereus polyrhizus) on tissue granulation and epithelialization in diabetes mellitus (DM) and non-DM Wistar rats: Pre eliminary study. International Journal of Science. 2017;32(1):309-20.

10. Li J, Wu T, Li N, et al. Bilberry anthocyanin improves the serum cholesterol in aging perimenopausal rats via the estrogen receptor signalling pathway. Journal of Food and Research. 2019; 10(1):3430. DOI: 10.1039/C9FO00639G

11. Ullah R, Khan M, Shah S A, et al. Natural antioxidant anthocyanins-A hidden therapeutic candidate in metabolic disorders with major focus in neurodegeneration. Molecular Diversity Preservation International Journal. 2019;11(6):1195. DOI: 10.3390/ nu11061195

12. McKleroy W, Lee T H, Atabai K. Targeting collagen degradation to treat tissue fibrosis. American Journal of Physiology Lung Cellular and Molecular Physiology. 2013;304(11):70921. DOI: 10.1152/ajplung.00418.2012

13. Suzanne E G, James F, Subhash V, et al. Collagen degradation in aged/photodamaged skin in vivo and after exposure to matrix metalloproteinase-1 in vitro. Journal of Investigative Dermatology. 2003;120(5):842-48. DOI: $10.1046 / \mathrm{j} .1523-$ 1747.2003.12148.x 